\title{
Blind Audio Source Separation Based On High Exploration Particle Swarm Optimization
}

\author{
Ali KHALFA ${ }^{1,2^{*}}$, Nourredine AMARDJIA ${ }^{1}$, Elhadi KENANE ${ }^{2}$, Djamel CHIKOUCHE ${ }^{2}$ \\ and Abdelouahab ATTIA ${ }^{3}$ \\ ${ }^{1}$ LIS Laboratory, Dept. of Electronics, Faculty of Technology, Ferhat Abbas University - Setif1, 19000, Algeria \\ ${ }^{2}$ LAAS Laboratory, Dept. of Electronics, Mohamed BOUDIAF University - M’Sila, 28000, Algeria \\ [e-mails: khalfaali2000@yahoo.fr, \{amardjia_nour, kenaneh,dj_chikou \}@yahoo.fr] \\ ${ }^{3}$ Dept. of Computer Science - Faculty of Mathematics and Informatics \\ Mohamed El Bachir El Ibrahimi University - Bordj Bou Arreridj, 34000, Algeria \\ [e-mail: attia.abdelouahab@gmail.com] \\ *Corresponding author: Ali KHALFA
}

Received May 20, 2018; revised September 11, 2018; accepted November 24, 2018;

published May 31, 2019

\begin{abstract}
Blind Source Separation (BSS) is a technique used to separate supposed independent sources of signals from a given set of observations. In this paper, the High Exploration Particle Swarm Optimization (HEPSO) algorithm, which is an enhancement of the Particle Swarm Optimization (PSO) algorithm, has been used to separate a set of source signals. Compared to PSO algorithm, HEPSO algorithm depends on two additional operators. The first operator is based on the multi-crossover mechanism of the genetic algorithm while the second one relies on the bee colony mechanism. Both operators have been employed to update the velocity and the position of the particles respectively. Thus, they are used to find the optimal separating matrix. The proposed method enhances the overall efficiency of the standard PSO in terms of good exploration and performance. Based on many tests realized on speech and music signals supplied by the BSS demo, experimental results confirm the robustness and the accuracy of the introduced BSS technique.
\end{abstract}

Keywords: Artificial Bee Colony, Blind Source Separation, Multi-crossover, Particle Swarm Optimization, BSS demo. 


\section{Introduction}

$\mathbf{B}_{\text {lind Source Separation (BSS) is a powerful tool that has been used to restore source signals }}$ from several observations without any prior knowledge about the source of the signals as well as their mixing process [1] [2]. Many algorithms have been proposed to solve the BSS problem depending on the mixture model: linear mixture [3], nonlinear mixture [4] and post-nonlinear mixture [5]. Moreover, BSS has been effectively applied in speech enhancement [6], microwave communication [7], satellite communication [8], image processing [9], image features extraction [10] and learning knowledge from massive community-contributed images [11]. In speech enhancement, BSS extracts sources from noisy speech signals. In biomedical signal processing, it focuses on extracting information using a set of bio-signal measurements made over time [12]. In mechanical systems, it permits to evaluate complex mode shapes which may occur in the real world [13].

Recently, several approaches have been proposed in literature for solving BSS problems. Peng Cheng XU et al. have designed a new reference-based contrast function based on negentropy approximations for the extraction of complex sources and also have introduced a new family of algorithms, denoted as Alg. 1 and Alg. 2, to maximize it [14]. Jiangong WANG et al. have proposed a BSS algorithm which is based on linear autocorrelations and joint diagonalization (LAJD), done through a merging diagonalizer of several average delayed covariance matrices at the optimal time delay [15].Yongjian ZHAO et al have proposed a framework using a sequential method based on second order statistics [16]. First, the authors estimate the source signal, then a deflation process permits to eliminate it from its mixtures. That can be used to recover one source signal or all signals in a specific order. The authors have validated the performance of this method via computer simulations. Jehad ABADNEH et al. have employed the Biogeography-Based Optimization (BBO) technique in order to optimize the contrast function which measures the statistical independence of the improved components [17]. In [18], Po-Sen HUANG et al. have used a deep learning model for monaural speech separation. The authors have proposed the joint optimization of a soft masking function and deep learning models, namely deep neural networks and recurrent neural networks (DNNs and RNNs). The proposed discriminative training criterion permits to improve the signal to interference ratio (SIR). This model attains 3.8 to $4.9 \mathrm{~dB}$ SIR gain compared to the non-negative matrix factorization (NMF) baseline, whereas maintaining good SDRs and SARs. Po-Sen HUANG et al. have explored the joint optimization of masking functions based on various deep learning architectures, including deep recurrent neural networks and deep neural networks for monaural source separation tasks such as speech separation, singing voice separation, and speech denoising [19]. The performance is optimized through combining a soft time-frequency mask layer with the networks in an end-to-end fashion while investigating a discriminative training criterion. Liangli ZHEN et al. have exploited a sparse coding in BSS, with n unidentified sources, to separate these sources from their $\mathrm{m}$ observed mixture signals, where $\mathrm{m}<\mathrm{n}$ [20]. The approach is based first on discovering some 1-D subspaces from the set consisting of all the time-frequency (TF) representation vectors of the observed mixture signals, then detecting the single source points SSPs in the TF plane, and after that, the estimation for the mixing matrix is done by grouping the mixture TF vectors at these SSPs. Finally, the source recovery is achieved by resolving a set of least squares problems. 
Also, evolutionary algorithms are successfully applied to solve several optimization problems in diverse fields. Genetic algorithms (GA) [21]-[24], the Particle Swarm Optimization (PSO) algorithm [25]-[27] and the Artificial Bee Colony (ABC) algorithm [28] have been applied to find the optimal separation matrix.

In this paper, the High Exploration PSO (HEPSO) algorithm [29] is used to optimize the objective function in order to estimate the coefficients of the separating matrix, to avoid local optima and to find the efficient global optimum. To demonstrate the performance of the introduced algorithm for the BSS problem, some simulation results are established.

The rest of this paper is organized as follows: section 2 depicts the BSS problem. Section 3 describes the PSO algorithm, followed by the Objective Function Evaluation given in Section 4. Section 5 consists of the proposed methodology while section 6 presents the experimental results. The conclusion and future work are given in the last section.

\section{The Blind Source Separation Problem}

The BSS is a famous process that is used in separating source signals and recovering them from an observed mixed signal. This process deals with the statistical properties of the source signals. The basic BSS model is shown in Fig. 1[30].

In our study, we are interested in the process of the optimization algorithm illustrated in the model diagram of Fig. 1. The chosen algorithm (HEPSO) is used to optimize the objective function in order to make output signals independent.

The BSS model is defined by:

$$
X=A . S
$$

where $X=\left[x_{1}, x_{2} \ldots \ldots x_{m}\right]^{T}$ is a vector containing observed signal $X$, $S=\left[s_{1}, s_{2} \ldots \ldots s_{n}\right]^{T}$ is a vector containing the original sources and $A$ is the mixing matrix with full column rank. The linear model can be defined as:

$$
X_{i}(t)=a_{k 1} s_{1}+a_{k 2} s_{2}+\cdots a_{k n} s_{n}, \quad k=1, n
$$

In this paper, we assume that the number of sources $n$ is equal to the number of mixtures $m$ $(m=n)$. In fact, when solving BSS problems, two assumptions are made. The first assumption is that the source signals are statistically independent and the second one is that only one source is permitted to have a Gaussian distribution because a linear combination of Gaussian signals is Gaussian and then in this case it is impossible to separate them. With the above assumptions, the BSS result has two inherent ambiguities [31]:

1. We cannot determine the variance of the independent components.

2. We cannot determine the order of the independent components.

In this study, our main goal is to separate the signals from each other. The order of the estimated signals is not important.

The unmixing matrix $\left(W_{i}\right)$ can estimate the original source given by: 


$$
y=W_{i} X
$$

In addition, Independent Component Analysis (ICA) method is very accurately when connected to BSS. It finds statistically independent components from multivariate data. There are many ways to perform ICA, including minimization of mutual information or maximization of non-gaussianity.

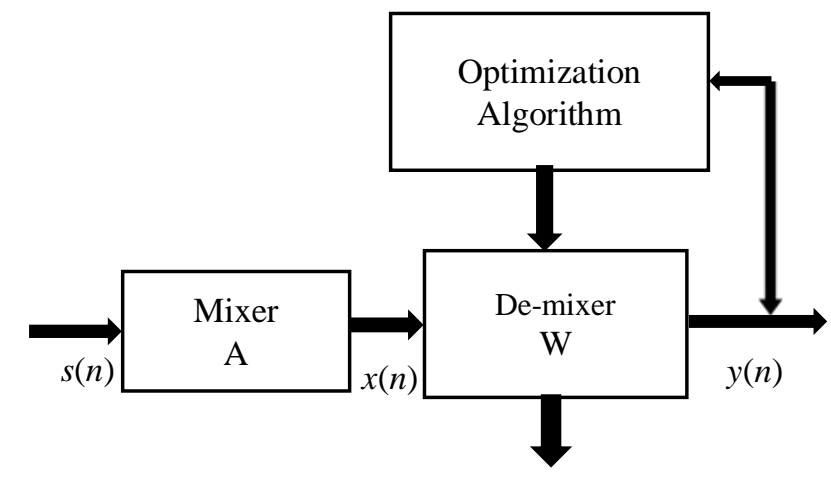

Fig. 1. The basic model diagram of the BSS process.

\section{Particle Swarm Optimization}

Swarm intelligence is one field of artificial intelligence that studies collective behavior and emergent properties of complex, self-organized and decentralized systems with social structure. The major inspiration behind the development of swarm intelligence stems directly from nature such as fish schools, bird flocks, ant colonies and animal herds [32]. The particle swarm optimization concept consists of that at each time step each particle changes its search direction based on two factors to discover the optimal solution. The first factor is its own best previous experience and the second is the best experience of all other members.

PSO has been effectively applied in many researches and applications. It is demonstrated that PSO is much easier to implement and converge faster compared to other methods [33]. The basic process of the PSO algorithm is initialization, fitness, update, construction, and termination. The process of PSO is finished if the termination condition is satisfied. The details are given in [34].

Mathematically, the particles are operated according to the following equations:

$$
\begin{aligned}
& \mathrm{v}_{\mathrm{i}}(\mathrm{t}+1)=\mathrm{wv}_{\mathrm{i}}(\mathrm{t})+\mathrm{C}_{1} \cdot \mathrm{r}_{1}\left(\mathrm{x}_{\text {Pbest }}-\mathrm{x}_{\mathrm{i}}(\mathrm{t})\right)+\mathrm{C}_{2} \mathrm{r}_{2}\left(\mathrm{x}_{\text {Pbest }}-\mathrm{x}_{\mathrm{i}}(\mathrm{t})\right) \\
& \mathrm{x}_{\mathrm{i}}(\mathrm{t}+1)=\mathrm{x}_{\mathrm{i}}(\mathrm{t})+\mathrm{v}_{\mathrm{i}}(\mathrm{t}+1)
\end{aligned}
$$

where $x_{i}(t)$ and $v_{i}(t)$ indicate respectively the position and velocity of particle $\mathrm{i}$ at iteration $\mathrm{t}$ (time step), $r_{1}, r_{2} \in[0,1], w$ the inertia weight is dynamically adjusted as proposed in [29] and is given in (8)

$$
\begin{aligned}
& C_{1}=C_{11}-\left(C_{11}-C_{1 f}\right)\left(\frac{t}{\max \text { itération }}\right) \\
& C_{2}=C_{12}-\left(C_{12}-C_{2 f}\right)\left(\frac{t}{\max \text { itération }}\right)
\end{aligned}
$$


$\mathrm{C}_{1 \mathrm{i}}$ and $\mathrm{C}_{2 \mathrm{i}}$ are the initial values of the learning factors $\mathrm{C}_{1}$ and $\mathrm{C}_{2}$ respectively while $\mathrm{C}_{1 \mathrm{f}}$ and $\mathrm{C}_{2 \mathrm{f}}$ are respectively their final values.

$$
\begin{aligned}
& w(f)=\frac{1}{\left(1+1.5 e^{-2.6 f}\right)} \\
& \mathrm{f}=\frac{\mathrm{d}_{\mathrm{g}}-\mathrm{d}_{\min }}{\mathrm{d}_{\max }-\mathrm{d}_{\min }} \in[0,1] \\
& d_{i}=\frac{1}{N-1} \sum_{j=1, j \neq i}^{N} \sqrt{\sum_{k=1}^{D}\left(x_{i}^{k}-x_{j}^{k}\right)^{2}}
\end{aligned}
$$

In order to compute $d_{\min }$ and $d_{\max }$, we can use an Euclidian metric via equation (10), where $d_{i}$ is the mean distance of particle $i$ to all other particles, $N$ and $D$ are the population size and the number of dimension, respectively; $d_{i}$ for the global best particle is shown as $d_{g}$.

\section{Objective Function Evaluation}

The fitness function proposed in this paper is based on kurtosis and mutual information. Kurtosis plays an important role in BSS and is used to measure the non-gaussianity of the signal and sort the independent components. Mutual information measures the dependence between components. To achieve the independence of the components, the mutual information must be at its minimum.

The mutual information is defined as follows:

$$
I\left(y_{1} y_{2}, \ldots . . y_{n}\right)=\sum_{i=1}^{n} H\left(y_{i}\right)-H(y)
$$

where $H\left(y_{i}\right)=-E \log p_{y i}\left(y_{i}\right)$ and $H(y)=-E \log y(y)$ are the entropies of the estimated audio source signals, $\mathrm{E}$ denoting the expectation operator and $p_{y}$ the density of the kurtosis of the estimated audio source signals that can be computed by the following formula:

$$
\operatorname{kurtosis}(y)=\sum_{i=1}^{n}\left|E\left(y_{i}^{4}\right)-3 E^{2}\left(y_{i}^{2}\right)\right|
$$

The fitness function can be expressed by:

$$
J(y)=I\left(y_{1} y_{2}, \ldots . . y_{n}\right)+\frac{1}{\sum_{i=1}^{n}\left|E\left(y_{i}^{4}\right)-3 E^{2}\left(y_{i}^{2}\right)\right|}
$$

When $\mathrm{J}(\mathrm{y})$ is maximized, estimated audio source signals are mutually independent.

\section{Proposed Methodology}

In the following part, the research paper describes the introduced BSS system used in problems' separation of several audio sources. Basically, the BSS system has been performed in four principal stages: (i) process of mixing the input audio sources, (ii) then, de-mix the output signals from the first stage using PSO and HEPSO methods (iii) after that, estimate the output sources by using equation (3) (iiii) finally evaluate the performance of the BSS system. The scheme of the introduced method is clearly illustrated in Fig. 2. 


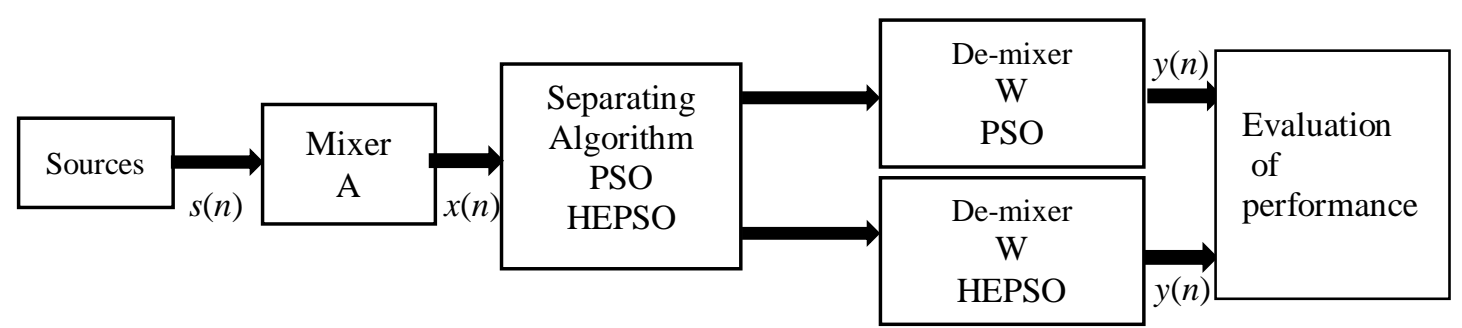

Fig. 2. Scheme of the proposed method.

\subsection{BSS Based on HEPSO Algorithm}

In this subsection, we introduce the proposed technique for BSS. We start with the $1^{\text {st }}$ stage in which initial population is produced. In the $2^{\text {nd }}$ stage the inertia weight (w) and the learning factors $\left(C_{1}, C_{2}\right)$ are calculated at each iteration. In the $3^{\text {rd }}$ stage, we evaluate the objective function of all particles. In the $4^{\text {th }}$ stage, the bee colony operator (equation (16)) is used only if $p_{1}<$ standard deviation or $p_{2}<$ $\frac{P_{B} \times t}{\max \text { iteration }}$, where $p_{1}, p_{2}$ would be assigned and $p_{B}$ is the bee colony probability, $\mathrm{t}$ is the current iteration and max iteration is the maximum number of iterations. On the $5^{\text {th }}$ stage, the multi-crossover will be generated if for each particle that is not selected in the preceding operation, another random number would be allocated. In the case of a particle that has $v<p_{c}$, the multi-crossover operator would generate a velocity or a new particle via equation (15), $p_{c}$ is the multi-crossover probability. PSO will generate other particles that are not selected neither for bee colony nor multi-crossover operations (equations (7) and (8)). On the $6^{\text {th }}$ stage, transform values are obtained from $x_{\text {best }}$ into the separation vector. In the $7^{\text {th }}$ stage, the orthogonalization process $W_{i}$ is performed via equation (14).

$$
W_{i}=W_{i} \times \operatorname{real}\left(\operatorname{inv}\left(W_{i} \times W_{i}^{T}\right)^{-\frac{1}{2}}\right.
$$

On the $8^{\text {th }}$ stage, we go back to the $3^{\text {rd }}$ stage and repeat the process until the stopping criterion is satisfied. Finally, in the $9^{\text {th }}$ stage, we compute the separated source using equation (3).

\subsection{Operators}

This subsection, introduce two operators. The first one is based on three parent chromosomes [35] and the second one is accomplished as a bee colony process [36]. These operators aim to ameliorate the process and leak from local minima.

\subsubsection{Operator1}

A new crossover method that consists of three parent chromosomes $[\theta 1, \theta 2, \theta 3]$ is suggested in this study, but it is not similar to the classical multi-crossover genetic algorithm proposed by Chang [35] which is based on only two chromosomes. We suppose that chromosomes are chosen from the population randomly. If chromosome $\theta_{1}$ has the smallest fitness value, the multiple-crossover is operated to generate a new chromosome $\theta_{1}^{\prime}$.

$$
\theta_{1}^{\prime}=\theta_{1}+r\left(2 \theta_{1}-\theta_{2}-\theta_{3}\right)
$$


where $r \in[0,1]$ is a random value. The first parent characterizes the best position of the group $\left(x_{\text {gbest }}(t)\right)$, the second parent represents the personal best position $\left(x_{\text {pbest }}\right)$ while the third parent is used to generate the new velocity for the selected particle $x_{i}$ via equation (16)

$$
v_{i}(t+1)=r\left[\frac{c_{2}}{2} x_{\text {gbest }}(t)-x_{\text {pbest }}(t)-x_{i}(t)\right]
$$

\subsubsection{Operator2}

The artificial bee colony (ABC) algorithm was developed by Karaboga and Basturk in 2005, by inspecting the behavior of real bees that find sources of food, called nectar, and share the information from these sources with the other bees in the nest. In this algorithm, artificial bees are defined and classified in three groups: employer bees (bees which look for the food), spectators (bees of observation) and scouts which are in charge of finding new food [36][37]. The ABC algorithm has five steps. In the first step, the bees start searching out space randomly to find a food source. In the second step and after finding a food source, the bees come to be an employer folder and begin to benefit from the inventive source. An employer bee replaces its location through local information and finds a neighboring food. Actually, the fitness of the position is estimated and if it has a better fitness, then it will be replaced with the old position. The third step deals with computing probability values which is implicated in the probabilistic selection depending on the fitness values of the food source. Finding operator is used in particle swarm optimization technique via equation (17).

$$
x_{i}^{d}(t+1)=x_{i}^{d}+(2 r-1)\left(x_{i}^{d}(t)-x_{j}^{d}(t)\right)
$$

where $r \in[0,1], d$ is a random number of length $[1$, dimension] and $j$ is a random number of length [1, number of particles].

\section{Experimental Results}

To show the performance of the proposed technique on the separation of speech and music signals, some experimental tests are undertaken and compared to PSO method results [33].

\subsection{Source Signals}

In this work, all speech signals and music signals are selected from the BSS demo [37] and sampled at $16 \mathrm{KHz}$. In the first experiment, we take two speech signals, the first one (poem_male_30s.wav) is pronounced by a man, while the second (sentence_female_28s.wav) is pronounced by a woman. In the second experiment, we take a music signal (music_Loophass_30s.wav) and a speech signal (henry_theater_male_30s.wav). In the third experiment we take music signals:

(music_mandolin_30s.wav) and (music_vivaldi_30s.wav).

In the initialization, the sensors and sources are set to 2 elements each. The $2 \times 2$ mixing matrix A is randomly chosen as:

$$
A=\left[\begin{array}{rr}
0.4701 & 0.6705 \\
-0.2742 & 0.5310
\end{array}\right]
$$




\subsection{Parameters Setting}

The initialization values of the parameters for the HEPSO proposed method are as follows: The population pop size is fixed to 100 , the problem has a dimension of $9(\mathrm{dim}=9)$, the probability of mutation $p_{B}$ is equal to 0.02 , the probability of crossover $p_{C}$ is fixed to 0.9 and the other combination values are fixed to

$$
C_{1 i}=2.5, C_{2 i}=0.5, C_{1 f}=0.5, C_{2 f}=2.5 \text {. }
$$

\subsection{Performance Measure}

In order to examine the performance of the proposed technique, we evaluate it using three performance indexes:

Source to Distortion Ratio (SDR) [21], Absolute Value of Correlation Coefficients (AVCC)) [39] and Mean Square Error (MSE) [36]. They are, respectively defined as follows:

$$
\operatorname{SDR}\left(y_{i}, s_{i}\right)=10 \log \left[\frac{\sum_{i=1}^{M}\left[y_{i}(t)\right]^{2}}{\sum_{i=1}^{M}\left[y_{i}(t)-s_{i}(t)\right]^{2}}\right]
$$

where $y_{i}$ are the separated signals, $s_{i}$ the original signals, with $\mathrm{M}$ samples.

$$
\operatorname{AVCC}=\left|\frac{\sum_{t=1}^{M} y_{i}(t) s_{k}(t)}{\sqrt{\sum_{t=1}^{M} y_{i}(t)^{2} \sum_{t=1}^{M} s_{k}(t)^{2}}}\right|
$$

\subsection{Simulation Results}

Experiment 1

A poem-male.wav and sentence-female.wave signals and their recovered ones are shown in Fig. 3.
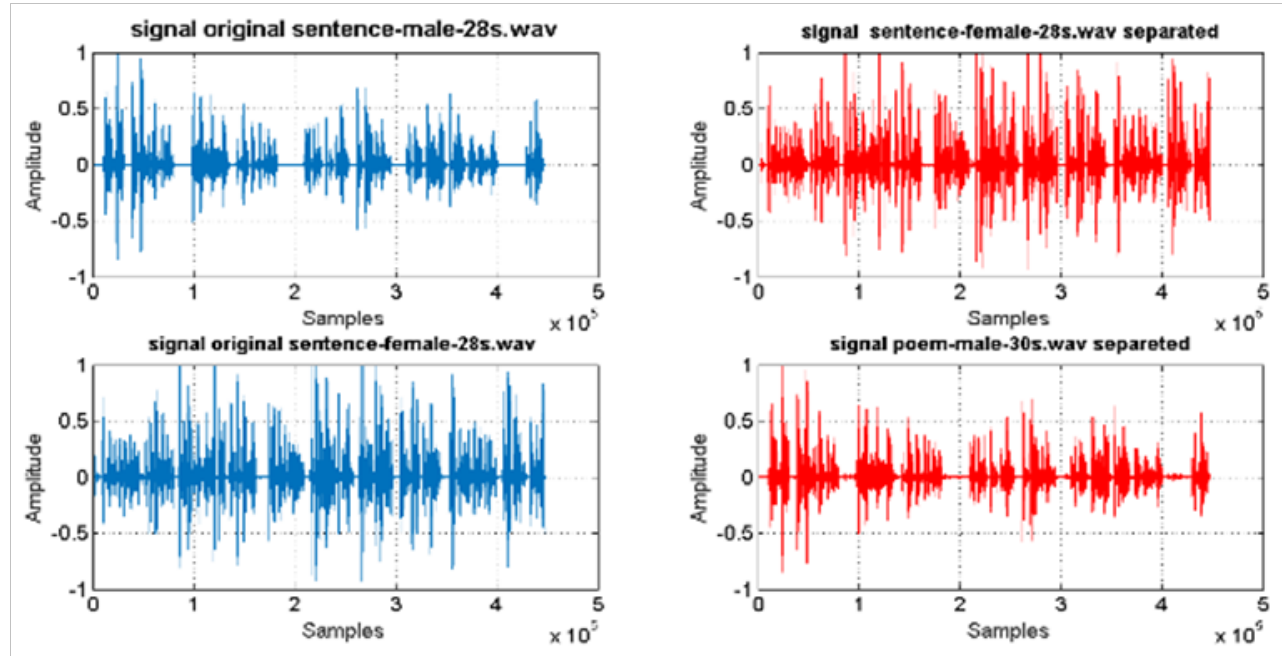

Fig. 3. Original and Separated signals of poem-male.wav and sentence-female.wav. 
Experiment 2

A music loophass.wav and henry theater male.wav and their recovered ones are shown in Fig. 4.
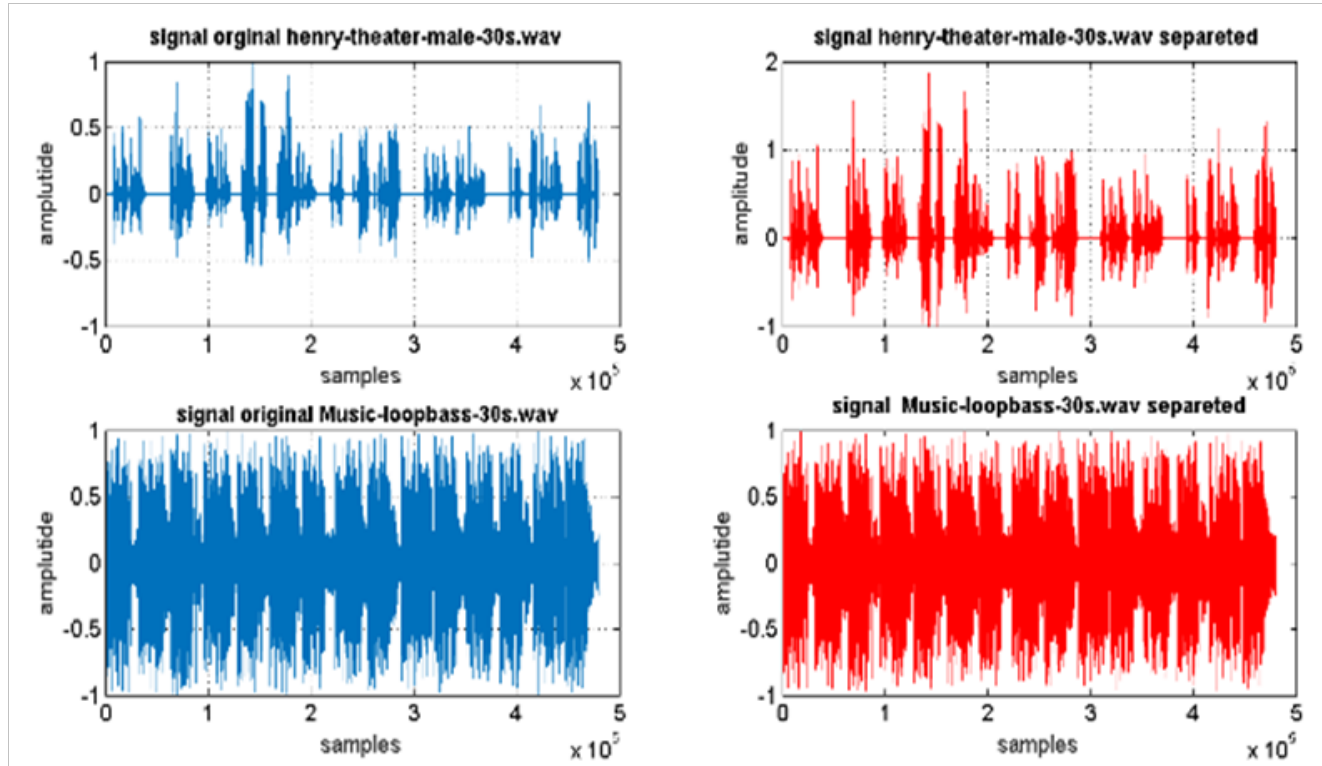

Fig. 4. Original and Separated signals of music loophass.wav and henry theater male.wav

Experiment 3

A music mandolin.wav and music vivaldi.wav and theirrecovered ones are shown in Fig. 5.
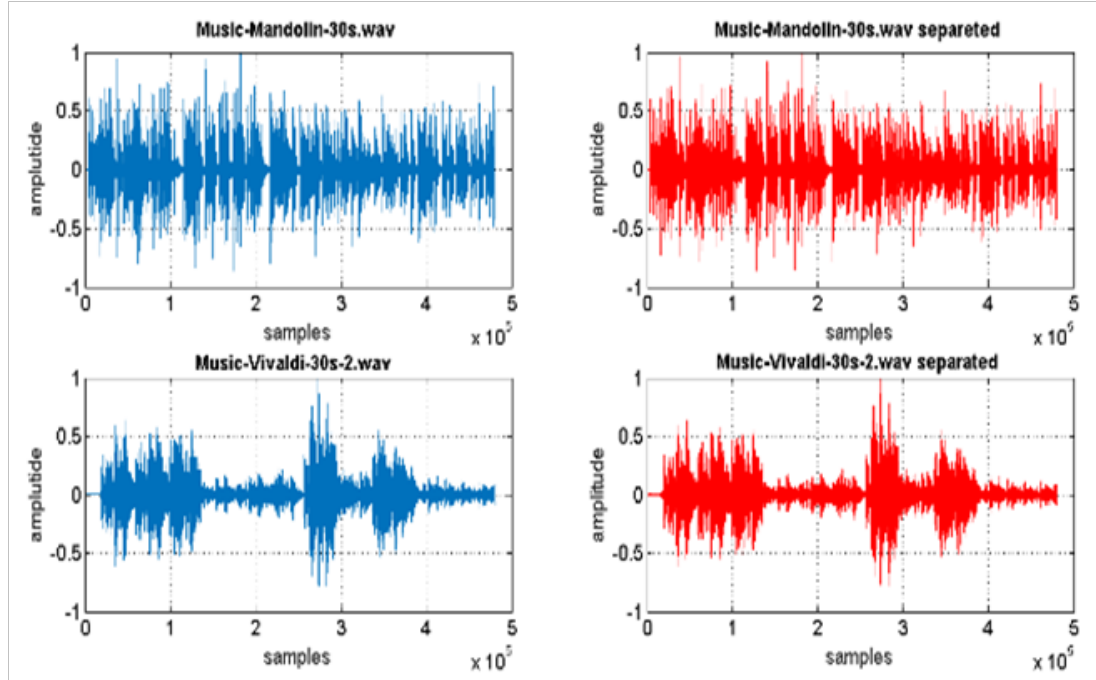

Fig. 5. Original and Separated signals of musicmandolin.wav andmusic vivaldi. wav.

From the experimental results we can deduce:

First, in figures 3 to 5 we see that the waveforms of the recovered speech signals and music signals are similar to the original ones. However, the music separated signals (Fig. 5) are a little less accurate.

Second, we prove the efficiency of the proposed algorithm by using performance indexes SDR, 
AVCC and MSE. The experimental results of the three experiments are summarized in Tables 1,2 and 3.

Table 1. SDR(dB) for the PSO and the HEPSO algorithm.

\begin{tabular}{|c|c|c|}
\hline Experiment & PSO & HEPSO \\
\hline Experiment 1 & & \\
\hline Speech s1 & 24.9632 & 48.7775 \\
\hline Speech s2 & 25.2020 & 39.4966 \\
\hline Experiment 2 & & \\
\hline Speech s3 & 19.2221 & 74.0782 \\
\hline Music s4 & 19.4236 & 23.6904 \\
\hline Experiment 3 & & \\
\hline Music s5 & 25.0062 & 26.1812 \\
\hline Music s6 & 26.0567 & 54.7541 \\
\hline
\end{tabular}

Table 2. AVCC for the PSO and the proposed algorithms

\begin{tabular}{|c|c|c|c|c|}
\hline \multirow{2}{*}{ Experiment } & \multicolumn{2}{|c|}{ PSO (Recovered Signals) } & Proposed algorithm (Recovered Signals) \\
\cline { 2 - 5 } & $\mathrm{y} 1$ & $\mathrm{y} 2$ & $\mathrm{y} 1$ & $\mathrm{y} 2$ \\
\hline Experiment 1 & & & & 0.0071 \\
\hline Speech s1 & 0.0435 & 0.9987 & 1.0000 & 0.9999 \\
\hline Speech s2 & 0.9989 & 0.0474 & 0.0071 & 1.00000 \\
\hline Experiment 2 & & & & 0.0027 \\
\hline Speech1 s3 & 0.9941 & 0.1038 & 0.0699 & 0.0031 \\
\hline Music s4 & 0.1063 & 0.9943 & 0.9977 & 1.00000 \\
\hline Experiments3 & & & & 0.9984 \\
\hline Music s5 & 0.0549 & 0.9988 & 0.0549 & \\
\hline Music s6 & 0.9984 & 0.0485 & & \\
\hline
\end{tabular}

Table 3. MSE for the PSO and the proposed algorithms

\begin{tabular}{|c|c|c|}
\hline Experiment & PSO & Proposed algorithm \\
\hline Experiment 1 & & $6.6862 \mathrm{e}-08$ \\
\hline Speech s1 & $1.7695 \mathrm{e}-04$ & $1.1463 \mathrm{e}-06$ \\
\hline Speech s2 & $8.9424 \mathrm{e}-05$ & \\
\hline Experiment 2 & & $2.2881 \mathrm{e}-10$ \\
\hline Speech1 s3 & $6.8208 \mathrm{e}-05$ & $3.9061 \mathrm{e}-04$ \\
\hline Music s4 & $9.7202 \mathrm{e}-04$ & \\
\hline Experiment 3 & & $4.7101 \mathrm{e}-05$ \\
\hline Music s5 & $6.1479 \mathrm{e}-04$ & $5.3490 \mathrm{e}-04$ \\
\hline Music s6 & $5.6638 \mathrm{e}-04$ & \\
\hline
\end{tabular}

This work has been compared to the previous studies that treat the problem of BSS separation. It has been clearly noticed that the proposed method HEPSO outperforms the GA+ kurtosis [21] in terms of SDR (shown in Table 4). In terms of AVCC measure the introduced method 
HEPSO achieves an excellent performance (100\%). Table 5 presents more details about the comparison accuracy of the proposed work with GA+ kurtosis [21]

Table 4. SDR(dB) for the GA+ kurtosis and theProposed method

\begin{tabular}{|c|c|c|}
\hline & GA+ kurtosis[21] & Proposed method \\
\hline \hline Speech s1 & 30.9869 & 48.7775 \\
\hline Speech s2 & 34.6346 & 39.4966 \\
\hline
\end{tabular}

Table 5. AVCC for the GA+ kurtosisand the proposed algorithms

\begin{tabular}{|c|c|c|c|c|}
\hline & \multicolumn{2}{|c|}{$\begin{array}{c}\text { GA+ kurtosis (Recovered } \\
\text { Signals) [21] }\end{array}$} & \multicolumn{2}{c|}{ Proposed $\begin{array}{c}\text { algorithm (Recovered } \\
\text { Signals) }\end{array}$} \\
\hline & $\mathrm{y} 1$ & $\mathrm{y} 2$ & $\mathrm{y} 1$ & $\mathrm{y} 2$ \\
\hline Speech s1 & 0.9996 & 0.0185 & 1.0000 & 0.0071 \\
\hline Speech s2 & 0.0282 & 0.9998 & 0.0071 & 0.9999 \\
\hline
\end{tabular}

\section{Conclusion}

In this paper, a blind audio source separation using HEPSO method was implemented and experimentally investigated. By using HEPSO, the separate sources have been estimated from their observed mixtures. On evaluation of performance of the implemented HEPSO, the BSS demo, which contains several examples of speech and music signals, has been used. The simulation results show that HEPSO overpowers the local minima problem and performs better in terms of global optimality in comparison with the standard PSO algorithm. The performance results clearly demonstrated that HEPSO outperforms GA+ kurtosis and also permitted a good separation to identify the source signals.

In our future work, we are planning to investigate other methods of optimizations such as the Firefly Algorithm (FA) in order to improve their performance accuracies.

\section{References}

[1] Zhao, W., Wei, Y., Shen, Y., CAO, Y., Yuan, Z., Xu, P., and Jian, W., "An efficient algorithm by kurtosis maximization in reference-based framework,” Radio engineering, vol. 24, no. 2, p. 544-551, 2015. Article (CrossRef Link).

[2] ZHAO, W., WEI, Y. M., SHEN, Y. H., YUAN, Z. G., XU, P. C., JIAN, W., “A novel Fast ICA method for the reference-based contrast functions,” Radio engineering, vol. 23, no. 4, p. 1221-1225, 2014. Article (CrossRef Link).

[3] REDIF, S., "Convolutive blind signal separation via polynomial matrix generalized eigenvalue decomposition,” Electronics Letters, vol. 53, no. 2, p. 87-89, Jan. 2017. Article (CrossRef Link).

[4] TALEB, A., “A generic framework for blind source separation in structured nonlinear models,” IEEE Trans. on Signal Processing, vol. 50, no. 8, p. 1819-1830, Aug. 2002. Article (CrossRef Link).

[5] TALEB, A., and JUTTEN, C., "Sources separation in post nonlinear mixtures," IEEE Transactions on Signal Processing, vol. 47, no. 10, p. 2807-2820, Oct. 1999. Article (CrossRef Link).

[6] YILMAZ, O. and RICKARD, S., "Blind Separation of Speech Mixtures via time-frequency masking," IEEE Transactions on Signal Processing, vol. 52, no. 7, p. 1830-1847, Jul. 2004. Article (CrossRef Link).

[7] A. Vergara, "Blind source separation of human body motion using direct conversion Doppler radar," in Proc. of Microwave Symposium Digest 2008 IEEE MTT-S International, p.1321-1324, 15-20 June 2008. Article (CrossRef Link). 
[8] I. R. Farah and M. B. Ahmed, "Satellite image analysis based on the method of blind separation of sources for the extraction of information," in Proc. of IEEE Xplore Conference: Geoscience and Remote Sensing Symposium,2002. IGARSS ‘02. 2002 IEEE International, Vol. 2, 2002.

Article (CrossRef Link).

[9] H. Snoussi and A. Mohammad-Djafari, "Fast joint separation and segmentation of mixed images," Journal of Electronic, vol. 13, p. 349-361, Apr. 2004. Article (CrossRef Link).

[10] LIU, Fan, TANG, Zhenmin, et TANG, Jinhui.,"WLBP: Weber local binary pattern for local image description,” Neurocomputing, vol. 120, p. 325-335, 2013.Article (CrossRef Link).

[11] LI, Zechao, TANG, Jinhui, et MEI, Tao., "Deep Collaborative Embedding for Social Image Understanding,” in Proc. of IEEE transactions on pattern analysis and machine intelligence, 2018. Article (CrossRef Link).

[12] V. Krishnaveni, S. Jayaraman, P. Kumar, K. Shivakumar, and K. Ramadoss., “Comparison of Independent Component Analysis Algorithms for removal of ocular artifacts from Electroencephalogram,” Measurement Science Review Journal, vol. 5(2), pp. 6779, 2005. Article (CrossRef Link).

[13] W. HUANG, S. WU, F. KONG and Q. WU, "Research on Blind Source Separation for Machine Vibrations,” Wireless Sensor Network, Vol. 1 No. 5, p. 453-457, 2009. Article (CrossRef Link).

[14] XU, Peng-cheng, SHEN, Yue-hong, et HUI, L. I., "New Negentropy Optimization Schemes for Blind Signal Extraction of Complex Valued Sources,” Radio engineering, vol. 24, no 1. 3, pp 861-865, 2015. Article (CrossRef Link).

[15] Jiangong Wang, Yuehong Shen, Hui Li, Hongyan Wei, Shiming Xu, "A Separation Algorithm for Sources with Temporal Structure Only Using Second-order Statistics,” vol. 22, no. 3, pp. 861-865, September 2013.

[16] ZHAO, Yongjian, JIANG, Bin, JIANG, Haining, et al., "Separating Signals with Specific Temporal Structure," In Proc. of 2017 International Conference on Computer Network, Electronic and Automation (ICCNEA). IEEE, p. 355-359, 2017. Article (CrossRef Link).

[17] ABABNEH, Jehadet IGUAL, Jorge., "Biogeography-based Optimization Algorithm for Independent Component Analysis," In Proc. of The International Conference on Computing Technology and Information Management (ICCTIM). Society of Digital Information and Wireless Communication, p. 348, 2014. Article (CrossRef Link).

[18] HUANG, Po-Sen, KIM, Minje, HASEGAWA-JOHNSON, Mark, et al., "Deep learning for monaural speech separation," In Proc. of Acoustics, Speech and Signal Processing (ICASSP), 2014 IEEE International Conference on. IEEE, p. 1562-1566, 2014. Article (CrossRef Link).

[19] HUANG, Po-Sen, KIM, Minje, HASEGAWA-JOHNSON, Mark, et al., “Joint optimization of masks and deep recurrent neural networks for monaural source separation," IEEE/ACM Transactions on Audio, Speech, and Language Processing, vol. 23, no 12, p. 2136-2147, 2015. Article (CrossRef Link).

[20] ZHEN, Liangli, PENG, Dezhong, YI, Zhang, etal.,"Underdetermined blind source separation using sparse coding," IEEE transactions on neural networks and learning systems, vol. 28, no 12, p. 3102-3108, 2017. Article (CrossRef Link).

[21] Y. Yang, X. Wang, D. Zhang, "Blind Source Separation Research Based on the Feature Distance Using Evolutionary Algorithms,” International Journal of Acoustics and Vibration, Vol. 19, No 4. 2014. Article (CrossRef Link).

[22] R.Malhotra, N. Singh, Y. Singh Punjab, "Genetic Algorithms: Concepts, Design for Optimization of Process Controllers,” Computer and Information Science, Vol. 4, No. 2, Feb 2011. Article (CrossRef Link).

[23] K. Sastry, D. Goldberg, and G. Kendall, E. K. Burke, "Search methodologies: introductory tutorials in optimization and decision support techniques,” Berlin: Springer, pp. 97-125, 2005. Article (CrossRef Link).

[24] P. Zheng, Y. Liu, L. Tian, Y. Cao, “A Blind Source separation Method Based on Diagonalization of correlation Matrices and Genetic Algorithm,” Fifth world Congress, Vol. 3, p. 2127-2131, June 2004.

[25] H. Zhou, C. Z. Chen, X. M. Sun, H. Liu, "Research on Blind Source Separation Algorithm Based on Particle Swarm Optimization,” advanced Materials Research, Vols.989-994, p. 1566-1569, 2014. Article (CrossRef Link). 
[26] Q. Bai, “Analysis of Particle Swarm Algorithm,” Computer and Information Science, vol. 3 No 1, Jan, 2010. Article (CrossRef Link).

[27] P. K. Tripathi, et al., "Multi-Objective Particle Swarm optimization with time variant inertia and acceleration coefficients,” Information Sciences, vol. 177, p. 5033-5049, 2007. Article (CrossRef Link).

[28] A.Ebrahimzadeh n, S.Mavaddati, "A novel technique for blind source separation using bees colony algorithm,” Elsevier Swarm and Evolutionary Computation, vol. 14, p. 15-20, 2014. Article (CrossRef Link).

[29] M.J. Mahmoodabadi, Z. SalahshoorMottaghi, A. Bagheri., "HEPSO: High exploration particle swarm Optimization,” information science, vol. 273, p. 101- 111, 2014. Article (CrossRef Link).

[30] R.Niva Das, Aurobinda Routray, Pradipta K. Dash., "ICA Methods for Blind Source Separation of Instantaneous Mixtures: A Case Study,” Neural Information Processing-Letters and Reviews, Vol. 11, No.11, November 2007. Article (CrossRef Link).

[31] Mazur and A. Mertins, "A sparsity-based the criterion for Solving the permutation ambiguity in convolutive blind source separation,” in Proc. of IEEE Int. Conf. Acoust., Speech, and Signal Processing, Prague, Czech Republic, p. 1996- 1999, May 2011. Article (CrossRef Link).

[32] MAVROVOUNIOTIS, Michalis, LI, Changhe, et YANG, Shengxiang., "A survey of swarm intelligence for dynamic optimization: Algorithms and applications," Swarm and Evolutionary Computation, vol. 33, p. 1-17, 2017. Article (CrossRef Link).

[33] Chien-Ching Chiu, Chien-Hung Chen \& Yu-Sheng Fan, "Image Reconstruction of a Buried Conductor by Modified Particle Swarm Optimization,” IETE Journal of Research, vol. 58(4), p. 284-291, 2012. Article (CrossRef Link).

[34] Kennedy, J. and Eberhart, R., "Particle swarm optimization," in Proc. of IEEE International Conference on Neural Networks, Nagoya, 1995. Article (CrossRef Link).

[35] W.D. Chang, “A multi-crossover genetic approach to multivariable PID controllers tuning," Expert Syst. Appl., vol. 33, no. 3, p. 620-626, 2017. Article (CrossRef Link).

[36] B. Akay, D. Karaboga, "A modified artificial bee colony algorithm for real-parameter optimization,” Inf. Sci., vol. 192, p. 120-142, 2012. Article (CrossRef Link).

[37] T.D. Seeley, “The Wisdom of the Hive: The Social Physiology of Honey Bee Colonies," Harvard University Press, 1995. Article (CrossRef Link).

D. Freedman, R. Pisani, and R. Purves, "Statistics, BSS demo,” W. W. Norton \& Company, 2007. 


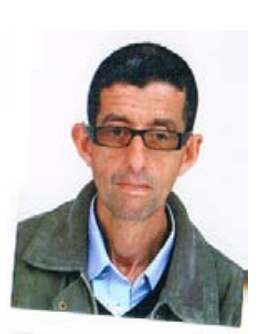

Ali KHALFA received the engineering degree in electronics in 1999 from the University of Setif, Algeria and his Master of Science degree in electrical engineering in 2007 from University of Setif, Algeria. He started his Ph.D. studies at the same university in 2007. He joined the Electronics Department, University of Msila as an assistant professor in 2013. He is a member of the LAAS laboratory, University of Msila. His research interests include mainly signal processing and focuse on blind source separation applications.

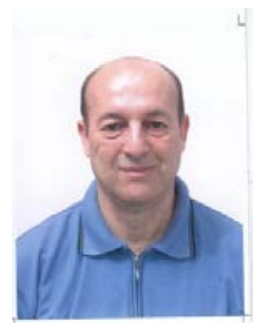

Nourredine AMARDJIA received the engineering degree in electronics in 1982 from ENPA (Ecole Nationale Polytechnique d'Alger), Algeria, his Master of Science degree in electrical engineering in 1985, from Fairleigh Dickinson University, New Jersey, USA, and his State Doctorate (Ph.D.) in communications in 2007 from University of Setif, Algeria. He joined the Electronics Department, University of Setif as an assistant professor in 1986. He has granted to the level of associate professor in 2007. He is a member of the LIS laboratory, University of Setif. His research interests include discrete transforms, image processing, filter design techniques, systolic architectures and fast algorithms for signal processing applications.

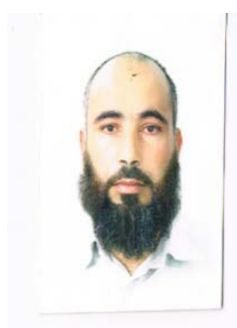

EL-Hadi KENANE was born in Selatna, BBA, Algeria, 1980. He accomplished his magisterial studies at Setif's university in 2006. He joined the Electronics Institute of the University of Msila, Algeria in 2011, where he currently works as an assistant professor. In 2017, he received the PhD in electronics from the same university. His research interests include mainly smart antennas, beamforming, stochastic methods of optimization, Antennas design and reconfigurable antennas. In addition to microwave circuit analysis and design, his research interests include DSP, and mobile telecommunications.

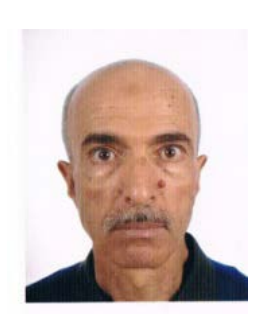

Djamel CHIKOUCHE obtained his DES degree (Bachelor of Science) in physical electronics in 1981 from Constantine University, Algeria, his Master of Science degree in electrical engineering in 1984 from Ohio State University, Columbus, Ohio, USA, and his State Doctorate (Ph.D.) in signal processing and communications in 2000 from University of Setif, Algeria. He joined the Electronics Department, University of Setif as an assistant professor in 1984. He has granted to the level of associate professor in 2000 and the level of professor in 2005 at the University of Setif. In 2006, he joined the Electronics Department, University of M'sila. He is a member of the LIS laboratory, University of Setif since 1996 til now. He conducted many reseach projects in signal and image processing. He published several papers in the areas of signal processing, systolic architectures, fast algorithms and image processing. His research interests are: signal processing, systolic architectures, fast algorithms, image processing, biomedical signals (EMG modeling), channel equalization, image compression, and radio-navigation.

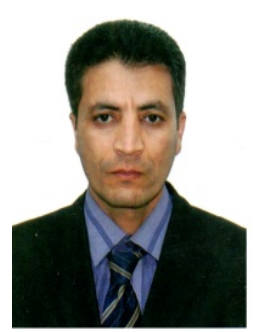

Abdelouahab ATTIA received, in 1997, his degree in Computer Science Engineering from Ferhat Abbes University - Setif 1 (UFAS), Algeria. From the same university, he received the Master degree in Computer Science in 2010 and his PhD degree in Computer Science in 2017. Since 2011, he is an assistant professor at the University of Bordj Bou Arrerridj. Algeria. His research interests include, Biometric systems, EEG classification, EEG/fMRI data fusion and fMRI data analysis. 